\title{
Climatic Elements \& Their Impact on Building Design
}

\author{
Prof. S K Gupta ${ }^{1}$, Ar. Nishant Nathani ${ }^{2}$ \\ ${ }^{1}$ Dean and Director, Amity School of Architecture \& Planning, Amity University Haryana, Manesar, Gurgaon, India \\ ${ }^{2}$ Assistant Professor, Amity School of Architecture \& Planning, Amity University Haryana, Manesar, Gurgaon, India
}

\begin{abstract}
Climate plays very important role in architecture designing. It has so many parameters to govern the climate as a whole. The resultant after applying the climate parameters is quite different than normal architectural design. While in architectural designing, the architects have to consider all the parameters together to achieve sustainable energy efficient and green building.
\end{abstract}

Keywords: Building design, Human Comfort, Climatic element

\section{Introduction}

Designing of sustainable green building is on priority now days. The climate plays an important role while designing a building so the consideration of climate while designing is of great importance. Climate varies with the places. The climate of a particular region is determined by the pattern of several elements \& their combinations. The assessment of climate parameters is to be considered in true manners to get the correct architectural design.

\section{Human Comfort}

The main elements for building design \& human comfort considered for this study are:-

\subsection{Air Temperature}

The rate of heating \& cooling of the earth's surface is the main factor determining the temperature of air. Since the air is transparent to all solar radiation therefore it has only an indirect effect on the air temperature. But the air layer, in direct contact with the warm ground is heated by conduction $\&$ this heat is transferred to upper layers by means of convection, turbulence \& eddies currents. These eddies currents \& winds brings large masses of air in contact with earth surface to be warmed up \& so on.

In winter: at nights, the earth is usually cool on account of long wave radiation to the sky and therefore the heat exchange is reversed and the air in contact with ground is cooled.

Water bodies are affected at a low rate than the land surface under same condition of solar radiation. So the land surface is warmer in summer and colder in winter than the sea surface on the same attitude.

Change in altitude also alters the temperature. On rising, the air moves from a higher pressure to lower one therefore it is cooled \& vice-versa. This difference is $1^{\circ} \mathrm{C}$ per 100 meters.

When water vapour condenses to form droplets, the latent heat is evolved in the process \& this heat thus reduces cooling as long as the condensation continues. This decrease is known as the lapse rate. The lapse rate varies with season and the time of the day, but on an average it is $0.6^{\circ} \mathrm{C}$ per 100 meter. Lapse rate is more during day near the ground as the air layer near the ground is warmer. This heated air expands and tends to rise, making lower air layer unstable and constantly mixing with upper layer. But at night the earth surface cools more than the air therefore the air near the ground becomes cool earlier than the upper layers. This results in a reversal of normal vertical temperature gradient near the ground. This phenomenon is known as surface inversion. Since the lower air layer is cool and heavy, this becomes stable and vertical air movement is suppressed. These conditions prevail in long nights, clear sky, dry air and in the absence of wind flow. The cold air near the ground tends to concentrate in low areas, such as valleys where the temperature may be many degrees lower than over high grounds.

\subsection{Humidity}

Atmospheric Humidity refers to the water vapour content of the atmosphere. Water yapour enters the air by evaporation, primarily from the ocean's surfaces. The vapour is carried \& distributed over the earth surface by the winds. The capacity of air for water vapour increases with the temperature, which results in uneven distribution of the vapour over the earth's surface. It is highest in the equatorial zone and decreases towards the poles.

\subsubsection{Absolute Humidity}

Weight of water vapour per unit volume of air terms $\left(\mathrm{g} / \mathrm{m}^{3}\right)$

\subsubsection{Specific Humidity}

Weight of water vapour per unit weight of air terms $\left(\mathrm{g} / \mathrm{m}^{3}\right)$.

\subsubsection{Vapour pressure}

Is the part of the whole atmospheric pressure that is due to the water vapour $(\mathrm{mm} . \mathrm{Hg})$.

\subsubsection{Relative Humidity (RH)}

The relative humidity at any temperature is the ratio of Actual Absolute Humidity to the maximum moisture capacity of the air at the temperature or the ratio of water vapour in the moisture to the water vapour in the saturated 


\section{International Journal of Science and Research (IJSR) \\ ISSN (Online): 2319-7064 \\ Index Copernicus Value (2013): 6.14 | Impact Factor (2015): 6.391}

air and is expressed in percentage e.g. if the Absolute Humidity of air for any given temperature is equal to $8 \mathrm{~g} / \mathrm{m}^{3}$ $\&$ the saturated air at same temperature contain $10 \mathrm{~g} / \mathrm{m}^{3}$ the ratio is $8: 10$ which when expressed in percentage, the $\mathrm{RH}$ will be $8 \times 100 / 10=80 \%$. When the air actually contains all the water vapour it can hold, it is said to be saturated $\&$ then relative humidity is $100 \%$.

Physiologically, vapour pressure of the air is the most convenient way to express the humidity conditions, because the rate of evaporation from the body is alpha to the vapour pressure difference between the skin surface and ambient air. The RH also affects the behavior of many buildings and their rate of deterioration. The Humidity does not affect directly the heat load operating on the body, but it determines the evaporative capacity of the air and hence the cooling efficiency of sweating.

The air in the lower layers of the atmosphere always contains a certain amount of water vapour resulting from evaporation of the earth's surface. The rate of evaporation depends primarily on temperature and wind. Observations in the tropics show that the surface of ocean evaporates $0.3 \mathrm{~m}$ deep layer of water in a year. However, there is a limit to the amount of water vapour the air can absorb, since the further evaporation will super saturate the air. As is known, if saturated air is heated it can absorb additional water vapour and on the contrary, if cooled saturated will change to super saturation. Thus it is clear that the ability of air to absorb \& retain the maximum amount of water is directly related to the temperature, values given in Table-1. The moisture content of the temperature can be expressed in several terms i.e.

Table-1: Amount of water vapour in air V/s its temperature

\begin{tabular}{|c|c|}
\hline $\begin{array}{c}\text { Air temperature Degree } \\
\text { Celsius }\end{array}$ & $\begin{array}{c}\text { Max. amount of water vapour } \\
\mathrm{g} / \mathrm{m} 3 \text { of air }\end{array}$ \\
\hline-20 & 0.94 \\
\hline-10 & 2.15 \\
\hline 0 & 4.57 \\
\hline+10 & 9.14 \\
\hline+20 & 17.36 \\
\hline+30 & 31.51 \\
\hline
\end{tabular}

\subsection{Precipitation}

Large-scale cloud formation and precipitation result from adiabatic cooling of large air masses and are affected greatly by the vertical stability of the air. A mass is raising air cools by expansion, eventually reaching its dew point. Then the large scale condensation occur forming clouds composed of innumerable tiny water droplets and sometimes icy crystals. Heavier enough droplets begins to fall and withstand the evaporative loss during the descent, thus finally precipitation occurs.

The basic purpose of planning/designing is to create a desirable \& efficient environment for good, pleasant and healthy living. A well designed building is the best possible compromise between the various aspect that govern the design i.e. the unit design, the grouping of independent units, building materials used, physical layout, landscaping, orientation with respect to sun and wind etc.
Table 2: Response of Human body to Temperature and Relative humidity

\begin{tabular}{|c|c|}
\hline Factors & Human body response (Feeling) \\
\hline \multicolumn{2}{|c|}{ Temperature Range } \\
\hline $35^{\circ} \mathrm{C} \&$ above & Very Hot \\
\hline $30^{\circ} \mathrm{C}-35^{\circ} \mathrm{C}$ & Desirable level \\
\hline $20^{\circ} \mathrm{C}-30^{\circ} \mathrm{C}$ & Cool \\
\hline Less than $20{ }^{\circ} \mathrm{C}$ & Cold \\
\hline \multicolumn{2}{|c|}{ Relative Humidity (RH) } \\
\hline $0 \%-25 \%$ & Very Dry \\
\hline $25 \%-50 \%$ & Dry \\
\hline $50 \%-75 \%$ & Humid desirable range $-+10 \%$ \\
\hline $75 \%-100 \%$ & Very Humid \\
\hline
\end{tabular}

Proper orientation of the single unit or building cluster plays a major role in increasing the efficiency of the housing unit. Traditionally, in any given time and place, climate has always played a very significant role in bringing out a characteristic building 'form' along with other aspects mentioned above. The climatic considerations were as important as other socio-technological aspects. The sloping roofs of the houses built on southern slops of cold hilly regions, the extended 'Aangan' (sit out verandah on residential street) in the areas of moderate climates and the essential building features of a hot dry climate such as basement, verandah, jharokhas, narrow streets as in Jaisalmer (Rajasthan) are a proof of this climate. A unit, when properly designed, can achieve a high degree of efficiency without the use of mechanical energy device and help to reduce the load on mechanical devices considerably. The human work output, nature and even health can directly affected by climate. Air temperature, radiation, humidity, air movement are various factors that can effect work out-put nature and even health get directly affected by the conditions of comfort or discomfort created by climate on human body explained in table-2.

When temperature is increased the condition would change from humid to dry. A humid or very humid situation can be very uncomfortable in the absence of proper air movement. In order to plan/design in any part of India, it is most desirable to get familiarize with the climatic conditions prevailing in the region. Climatic data for Delhi region:

A) Latitude - $28^{\circ}-85^{\prime}$

B) Longitude - $77^{\circ}-12^{\prime}$,

C) Mean Sea Level - 218 m elevation

D) Mean Rain Fall - 666.6 mm

Table 3: Seasons in Delhi

\begin{tabular}{|c|c|c|}
\hline S & Season & Effect \\
\hline 1 & $\begin{array}{c}\text { Cool \& cold temperate: } \\
\text { December to February }\end{array}$ & $\begin{array}{c}\text { Heat desirable both at day \& night } \\
\text { time. Sit out in sun during day time } \\
\text { quite desirable. }\end{array}$ \\
\hline 2 & $\begin{array}{c}\text { Temperate Season: } \\
\text { Sept. - Dec. }\end{array}$ & $\begin{array}{c}\text { Comfortable conditions prevail } \\
\text { during evening \& morning. }\end{array}$ \\
\hline 3 & $\begin{array}{c}\text { Hot Arid Season: } \\
\text { April - June }\end{array}$ & $\begin{array}{c}\text { Low humidity, high air temperature } \\
\text { very uncomfortable conditions } \\
\text { prevail. Cooling desirable especially } \\
\text { during day time. Hot dry sun must } \\
\text { be kept out. Sleeping out on open } \\
\text { terrace desirable. }\end{array}$ \\
\hline 4 & $\begin{array}{c}\text { Warm Humid } \\
\text { (Monsoon) }\end{array}$ & $\begin{array}{l}\text { Air temperature somewhat low, high } \\
\text { humidity, bearable discomfort, free } \\
\text { air movement very desirable. Cross } \\
\text { ventilation of air very comfortable. }\end{array}$ \\
\hline
\end{tabular}




\section{International Journal of Science and Research (IJSR) \\ ISSN (Online): 2319-7064 \\ Index Copernicus Value (2013): 6.14 | Impact Factor (2015): 6.391}

For Delhi region the building is best oriented with respect to sun when its longer axis is placed East - West \& with respect to wind when the axis is placed North - South. The combined effect with respect to sun and wind shall be best suited when the shorter axis is at inclination of 20 degree East of South.

Shading /louvers by chajjas and fins would ensure the entry of the winter sun, cutting out the undesirable summer sun. Shading/louvers can also be embraced by proper plantation. Reduction in heat reflection by using proper paving material and by choosing correct building materials, their colour \& texture, minimizing the dimensions of East-West and at the same time placing the non critical areas such as toilets, stair cases, stores etc. on these faces.

Courtyards, verandah \& porch are effective in mitigating the summer heat effect. A courtyard encloses a cushion of air which retains the cool of earth, shaded from the sun. For this reason a courtyard with a longer East - West dimension is not so effective as the one with a shorter East -West direction, where the courtyard is exposed to the summer sun for shorter time. For the same reason it may be that narrow street tend to remain shadier $\&$ hence cooler in summer.

Air movement affects body cooling. It does not decrease the temperature but causes a cooling sensation due to heat loss by convention from body $\&$ due to evaporation from body.

Table 4: Effect of wind sped on human body

\begin{tabular}{|c|c|}
\hline $\begin{array}{c}\text { Wind Speed } \\
\text { (meter/ second) }\end{array}$ & Effect on human body \\
\hline $0.00-0.25$ & Unnoticed \\
\hline $0.25-0.50$ & Pleasant \\
\hline $0.50-1.00$ & $\begin{array}{c}\text { Generally pleasant but causing awareness } \\
\text { of air moment }\end{array}$ \\
\hline $1.00-1.50$ & Slight draft effect to annoying drafty \\
\hline $1.50-$ above & Require corrective measure \\
\hline
\end{tabular}

- Vapour pressure is exerted by quantity of water vapour in air - More than $15 \mathrm{~mm}$ of $\mathrm{Hg}$ - People feel depressed. Over $15 \mathrm{~mm}$ of $\mathrm{Hg}$ Vapour Pressure (V.P.) each additional $\mathrm{mm}$ of V.P. can be counter acted with 0.45 meter / second wind.

- Evaporation decreases Dry Bulb Temperature (DBT). The temperature decrease caused by evaporation of added moisture will restore comfort temperature. The Bio climatic chart is plotted with DBT on one axis \& R.H. on the other then in the middle is comfort zone.

- The condition determined by DBT \& R.H. can be plotted. If plotted point falls in comfort zone we feel comfortable in shade (Table-5).

- If it is outside, higher than upper perimeter wind in needed.

- If temperature if high \& R.H. low we feel dry \& hot then wind is of little help, so evaporative cooling is required. This can be done by adding grains of moisture / pound of air to reduce temperature.

- At lower perimeter - radiation is needed.
Table 5: Chart showing different levels of DBT and RH

\begin{tabular}{|c|c|c|}
\hline \multirow{2}{*}{1} & DBT 75\% & \multirow{2}{*}{ Comfort zone } \\
\hline & R.H. $70 \%$ & \\
\hline \multirow{2}{*}{2} & DBT $75 \%$ & \multirow{2}{*}{$280^{\prime}-0$ ' wind to counter act V.P. } \\
\hline & R.H. $50 \%$ & \\
\hline \multirow{2}{*}{3} & DBT $50 \%$ & \multirow{2}{*}{$260^{\prime}-0^{\prime}$ BTU / $\mathrm{hr}$ sun radiation } \\
\hline & R.H. 56\% & \\
\hline \multirow{2}{*}{4} & DBT 75\% & \multirow{2}{*}{ Comfort zone } \\
\hline & R.H. 50\% & \\
\hline \multirow{2}{*}{5} & DBT $87 \%$ & \multirow{2}{*}{$\begin{array}{l}\text { By two layers - } 300 \text { '- }-0 \text { ' wind evaporative } \\
\text { cooling by adding } 8 \mathrm{~g} \text { moisture / lb of air }\end{array}$} \\
\hline & R.H. $30 \%$ & \\
\hline \multirow[b]{2}{*}{6} & DBT 95\% & \multirow{2}{*}{$\begin{array}{c}\text { Comfort cannot be achieved by wind alone } \\
\text { even } 700 \text { FPM wind have to supplemented by } \\
9 \mathrm{~g} \text { moisture/ lb of air }\end{array}$} \\
\hline & R.H. $20 \%$ & \\
\hline
\end{tabular}

\subsection{Solar Radiation}

This is an electromagnetic radiation of different wave lengths and is measured in a unit called microns $(=1 / 1000$ of millimeter). The quantity of heat transmitted in one minute to $1 \mathrm{~cm}^{2}$ of earth surface is defined as solar constant which is equal to 2 cal per $\mathrm{cm}^{2}$ per minutes. Solar energy is transmitted as:-

Ultra Voilet (short waves) $<0.40$ micron

Infra Red (long waves) $>0.76$ micron

Most of the radiation is perceived as heat \& only an insignificant part as visible light (visible to eye) 0.4 to 0.76 micron. As radiation penetrations the earth atmosphere its intensity is reduced due to:-

\subsubsection{Absorption}

Radiation is absorbed in the atmosphere according to wave length. U.V. are absorbed by ozone I.R - by water vapour \& $\mathrm{CO}_{2}$

\subsubsection{Reflection}

Takes place from water droplets. Clouds also reflect back considerable fraction of radiation to outer space \& the remaining reaches earth surface in diffused form.

\subsubsection{Scattering}

When the light impinges on molecules, similar or smaller then the wave length, radiation is reflected \& diffused in space. Smaller molecules scatter shorter wave length i.e. blue \& violet giving blue color to sky. When the atmosphere contain larger particles of dust the air turbidity is increased which scatter long wave radiation i.e. yellow \& red giving white color sky.

Therefore the earth received considerably less solar energy due to various above losses.

- Part of the solar radiation is reflected by surface of clouds.

- Part is absorbed by atmospheric ingredients.

- Some is scattered by molecules in the atmosphere but some of this is regained as diffused radiation.

- Part of the radiation received by earth surface is reflected but most is absorbed $\&$ changes to heat $\&$ raise the temperature of air, ground \& surrounding objects.

Of the total amount of solar energy reaching the earth, the atmosphere absorbed $15 \%$, consequently the depletion of solar radiation by dispersion \& absorption for different 


\section{International Journal of Science and Research (IJSR) \\ ISSN (Online): 2319-7064 \\ Index Copernicus Value (2013): 6.14 | Impact Factor (2015): 6.391}

latitudes varies greatly. This is dependent on the incident angle of the sun's rays.

Table 6: Depletion of Radiation V/s Incident angle \& length of Path traversed by Sun rays

\begin{tabular}{|c|c|c|c|c|c|}
\hline Incident angle of Ray & $90^{\circ}$ & $50^{\circ}$ & $30^{\circ}$ & $10^{\circ}$ & $00^{\circ}$ \\
\hline Length of path traversed by ray & 1 & 1.3 & 2 & 5.56 & 35.4 \\
\hline Degree of radiation depleted & $25 \%$ & $31 \%$ & $44 \%$ & $80 \%$ & $100 \%$ \\
\hline
\end{tabular}

\subsection{Long Wave Radiation to the sky}

Long wave radiation is emitted by the surface of the earth to the atmosphere \& outer space. The intensity depends on the difference between the temperature of the earth surface and of the absorbing. The long wave radiation is emitted in all the directions by the gases in the atmosphere \& the downward component of this is absorbed by the earth. In the atmospheric gases, water vapour is the principle long wave radiation absorber along with $\mathrm{CO}_{2}$ which is less important.

The difference between the discharge of radiation from earth surface \& that emitted back to earth by the atmosphere is net radiation heat loss. When the sky is overcast this loss as the water particles in the clouds absorbs \& emitted the whole long wave radiation / spectrum emitted by the earth, in contrast with the limited absorption by water vapour in case of partially cloudy overcast sky where all the radiation given out by the earth is absorbed at the base of the cloud. Thus the net radiation heat loss is high when the atmosphere is clear and dry.

For the radiation balance of a city, reflected radiation is of great importance. Its magnitude depends on the intensity of direct solar irradiation \& the reflection factor. This reflection factor of building materials, soil, green spaces etc. depends on the color, texture \& other physical properties of the surface.

Light Concrete $-30-35 \%$.

Light Marble - $45 \%$.

Lime Stone - $50-65 \%$.

Rough grey Asphalt - 25\%.

Lawn - $20 \%$

In urban areas these surfaces are the additional source of reflection heat and so substantially raise the heat load.

\subsection{Wind}

The character \& distribution of winds over a region are determined by several factors. The main determinants are:-

a) Seasonal global distribution of air pressure.

b) Rotation of earth.

c) Daily variations in heating \& cooling of land and sea.

d) Topography of the region and its surroundings.

The wind flow is caused due to high \& low air pressure areas. The main cause of the pressure belts is the uneven distribution of solar radiation over the earth and the resulting variation in surface heating. On the equatorial regions, a large quantity of radiations is received $\&$ the air is heated above the level of air in adjacent regions. This heated air expands and is lifted upwards, leaving a belt of low pressure to wards which air flows from the surrounding regions. As the centre line of the maximum radiation zone in each hemisphere is shifted in summer towards the subtropics, the low pressure belt also moves accordingly. The distribution of land masses \& oceans in these regions determines the position of maximum heating zone \& consequently the pressure belts.

Air flows from higher pressure to lower pressure zones. The permanent \& semi- permanent regions of high pressure are sources of large masses of air which acquire specific physical characteristics according to the nature of the surface on which they rest.

The main regions generating such air masses are:-

a) The polar regions (throughout the year).

b) The cold land masses of Asia, North Africa \& North America (in winter).

c) The subtropical high pressure belts, particularly over the ocean (in summer).

\subsubsection{Trade winds}

Originates in the sub tropical high pressure regions of the two hemisphere and converge at inter tropical front forming the low pressure equatorial belt. These winds have similar temperature, humidity and flow to

- South West in North hemisphere \&

- North West in South hemisphere.

Over most of the oceans these winds produce small disturbances owing to constant direction and speed (15 to 30 $\mathrm{km} / \mathrm{hr}$ ), but over the Indian Ocean the direction of winds are reversed by monsoons in summer.

\subsubsection{Westerly's winds}

Also have their origin in the subtropical regions \& flows towards sub arctic low pressure regions \& converge at polar fronts. Due to large difference of temperature of westerly's $\&$ polar winds, the fronts are stormy.

\subsubsection{Polar winds}

These winds are formed by the cold air masses spreading out from the polar and arctic high pressure regions.

\subsubsection{The Monsoon Winds}

The difference between the annual mean temperature patterns over land \& sea produces the winter land winds \& summer sea winds known as monsoon.

\subsubsection{Land \& Sea Breezes}

During the day the air over land is heated more than that over sea surfaces on the same latitude. The cold sea air replaces the rising warmer air. At night this process is reversed. These winds are known as breezes.

\subsubsection{Mountain \& Valley Winds}

In mountain areas local thermal differences result in local wind patterns. The winds are directed up the mountain at day time \& down at night. The air near the mountain surface is heated mere than the free atmosphere at the same height \& so rises up at day time $\&$ at night the process is reversed. 


\section{International Journal of Science and Research (IJSR) \\ ISSN (Online): 2319-7064 \\ Index Copernicus Value (2013): 6.14 | Impact Factor (2015): 6.391}

Table 6: Characteristics of Wind Force \& Speed

\begin{tabular}{|c|c|c|}
\hline Description & Speed (meter/sec) & Effect of wind on land \\
\hline Light air & $00.00-00.20$ & Smoke rises vertically \\
\hline Light Breeze & $00.30-01.50$ & $\begin{array}{c}\text { Direction of wind } \\
\text { indicate by movement } \\
\text { of smoke }\end{array}$ \\
\hline Gentle Breeze & $03.40-05.40$ & $\begin{array}{c}\text { Resting of leaves wind } \\
\text { on face }\end{array}$ \\
\hline Moderate Breeze & $05.50-07.90$ & $\begin{array}{c}\text { Raising of dust, } \\
\text { movement of trees \& } \\
\text { branches }\end{array}$ \\
\hline Fresh Breeze & $09.00-10.70$ & Small trees sway \\
\hline Strong Breeze & $10.80-13.80$ & Wires hum \\
\hline Moderate Gale & $13.90-17.10$ & $\begin{array}{c}\text { Walking becomes } \\
\text { difficult }\end{array}$ \\
\hline Fresh Gale & $17.20-20.70$ & $\begin{array}{c}\text { Branches are broken, } \\
\text { walking difficult }\end{array}$ \\
\hline Whole Gale & $24.50-28.40$ & Damage roofs \\
\hline Storm & $28.50-32.60$ & Severe damage \\
\hline Hurricane & $32.70-$ above & Severe destruction \\
\hline
\end{tabular}

In the Delhi region, the prevalent wind direction for the year round is from North West. The hot dry winds of May tend to blow from North \& west \& the cool winds of Dec./Jan tend to come from the West. The only exception to this direction is the monsoon months of late July - August, when the wind blows from the East. While orienting a unit for wind, best results would be obtained if the window surface is perpendicular to the directions of the wind. However, if the face needs to be turned away from this optimum, a turn of up to 60 degrees away from the perpendicular direction would reduce the velocity by $30 \%$. Thus, the loss of benefit is not so much as in the case of solar orientation.

Cross ventilation or through movement of air current is highly desirable especially in the hot humid period of during 7 immediately after the monsoon season. This movement should be ensured at sill level or lower if natural ventilation is to be of any use while sleeping at night. Air circulating at higher levels is relatively useless.

Wind velocity through the dwelling unit can be increased by permitting the wind through small opening on the wind ward side and a larger one on the lee ward side (ratio of 1:2.5). This requirement alone makes it necessary to have controllable opening on both the opposite faces.

Since the windows are thin glass surfaces, they also become heat transmitters. For this reason, the window area must be kept to an optimum $\left(1 / 8^{\text {th }}\right.$ or $1 / 10^{\text {th }}$ of floor area).

The temperature difference that exists between the air inside the dwelling unit $\&$ the air outside, due to the disparity in weight causes the warmer air to rise, by displacement. This movement caused is called the stack effect. It is this effect that causes the air current inside the dwelling unit to move.

For a site which has several buildings, some of them, tend to come in the way of the direct wind movement line of the others. On the leeward side of the building 'eddies' zone of weak \& indefinite air current, are created. The depth of an eddy is determined by several factors such as the height of the building, the depth of the building, the face on which the wind is hitting it \& the angle at which the wind meets the face of the building. While planning a group of buildings on one site an attempt must be made to keeps one building out of the wind shadow of the other.

\subsection{Condensation \& precipitation}

When air containing a given amount of water vapour is cooled, its moisture holding capacity is reduced, increasing the R.H. until it becomes saturated. The temperature at which becomes saturated is known as the dew point. The dew-point at a given atmospheric pressure depends only on the vapour pressure of the air. Cooling of the air may be affected by three processes:-

1) Contact with cooler surfaces.

2) Mixing with cooler air.

3) Expansion associated with rising air currents.

The first two processes result in Dew \& Fog formation, the third one can cause large-scale precipitation.

\subsubsection{Dew}

Cooling by contact with colder surface is limited to the lower air layers. When condensations result, it takes the form of dew on the cold surface.

\subsubsection{Fog}

Fog is formed when the air does not come in direct contact with the cold surface and it is cooled below the dew point.

The conditions promoting the formation of fog are:-

- Cloudless sky, which promote long wave radiation to outer space \& cooling of the ground \& lower layers.

- A temperature inversion near the ground, which prevents vertical mixing of lower air layer with upper layers.

- Absence of winds, which may also prevent heating of the air layer by nertical mixing.

Fog is thicker \& more prevalent in valleys \& topographic depressions where the colder, heavy air tends to collect. This also occurs in coastal regions with shore winds bringing moist air in contact with a colder land surface.

\section{Conclusions}

Climatic points are to be discussed above all important while designing the dwelling unit. It is look after the location, surrounding, sun path, rail fall, wind \& etc. The professional architects must be considered the all the points while designing the buildings. Even this study will be used in education extensively to make the young architects aware of these parameters. The students shall be used these factors while designing the buildings. The resultant of these factors provides the masses of society better \& workable solutions in practical life. Pedagogy of green building should start from very initial and grass root level only then it will be possible for architects and engineers to convince their client to go ahead with green building.[4]

\section{References}

[1] Givoni, B., 1969. Man,Climate \& Architecture, Elsevier Publishing Company Limited. 


\section{International Journal of Science and Research (IJSR) \\ ISSN (Online): 2319-7064}

Index Copernicus Value (2013): 6.14 | Impact Factor (2015): 6.391

[2] Koenigsberger,O.H., Ingerrsoll,T.G., Mayhew, A.,Szokolay,S.V.,1973.Mannual of tropical Housing \& Building Part I.Climate Design,Orient Longman Pvt.Ltd.

[3] Krishanan,A.(ed), Baker, N.,Yannas, S.,Szokoly,S.,2001. Climate Responsive Architecture - A Design Handbook for Energy Efficent Buildings, Tata McGraw-Hill Publishing Company Limited, New Delhi.

[4] SK Gupta, Mustakeem R Khan, Nishant Nathani, Pragnya Prakash, Pedagogy for Green Building: India, International Journal of Environmental Research and Development. , pp 27 - 32 ,Volume 4, Number 1 (2014)

\section{Author Profile}

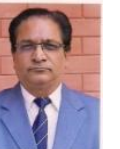

Prof. S K Gupta has completed his B.Arch. \& MURP from IIT Roorkee. After his Post graduation he worked with Ansal Group as a chief Architect then Retired from Chandigarh college of Architecture, Chandigarh as a Principal. At present he is Director in Amity School of Architecture \& Planning, Amity University Haryana.

Ar. Nishant Nathani has completed his B.Arch. from VTU, Belgaum and then Post Graduated from IIT Roorkee. Then he worked with Architect Hafeez Contractor. At present he is Asst. Professor, Architecture in Amity School of Architecture \& Planning, Amity University Haryana. He has won Yuva Ratna Award, Pidilite Award for Excellence and a design competition organized by Sarv Shiksha Abhiyan, Haryana. 